\title{
Smoking Lung Cancer Patients and Tobacco Cessation - Is the Current Treatment in Germany Sufficient?
}

\author{
Rauchende Lungenkrebspatienten und Tabakentwöhnung - Ist die aktuelle \\ Versorgung in Deutschland ausreichend?
}

Authors

Institutions
K. Vitzthum ${ }^{1,2}$, L. Thielke ${ }^{4}$, A. Deter ${ }^{2}$, T. Riemer ${ }^{4}$, S. Eggeling', W. Pankow ${ }^{1}$, S. Mache ${ }^{3}$

${ }^{1}$ Vivantes - Netzwerk für Gesundheit GmbH, Berlin

${ }^{2}$ Institute of Occupational Medicine - Charité - Universitymedicine Berlin

${ }^{3}$ Institute of Occupational, Social and Environmental Medicine - Hamburg

${ }^{4}$ Humboldt University Berlin - Institute of Psychology received 21.5 .2015 accepted after revision 5.8.2015

\section{Bibliography}

Dol http://dx.doi.org/ 10.1055/s-0034-1392960

Published online: 23.9 .2015

Pneumologie 2015; 69: 667-672

(c) Georg Thieme Verlag KG

Stuttgart $\cdot$ New York

ISSN 0934-8387

Corresponding author

Dr. Karin Vitzthum

Vivantes Netzwerk für

Gesundheit $\mathrm{GmbH}$

Rudower Straße 48

12351 Berlin

Germany

karin.vitzthum@vivantes.de

\section{Abstract}

$\nabla$

Lung cancer is the most preventable neoplastic disease for men and women. The incidence rate per year is 14.000 in Germany. Smoking is the main risk factor for the onset of lung cancer and for a share of $90 \%$ of cases, lung cancer is associated with smoking. Recent studies have shown that the time slot of diagnosing lung cancer is a teachable moment for tobacco cessation interventions. The therapy that was rated most effective was a combination of cognitive behavioral therapy and pharmacotherapy (e.g. NRT, Bupropion, Varenicline).

We examined the smoking status of all patients undergoing lung cancer surgery in 2011, 2012 and 2013 in this study. A retrospective semi structured interview via telephone was conducted regarding smoking habits and current quality of life. 131 patients ( $36.6 \%$ female, average age of 68.7 years) of an urban German hospital were included.

Results showed a relapse rate of $22.3 \%$, while $86.2 \%$ used to be highly addicted smokers; A multivariate analysis of covariance (MANCOVA) indicated a significant overall impact of smoking status on quality of life with a medium effect size, controlled for age, gender, living conditions, tumor stage, duration of smoking abstinence, type of cancer therapy, type of resection method, and the time period between the date of surgery and of the survey. Two thirds of all smokers did not see an association between their habit and their disease.

So far motivation to quit and long term abstinence rates are not sufficiently established even among seriously sick patients in Germany; further initiatives should focus on new and more intense interventions and educational strategies.

\section{Zusammenfassung \\ $\nabla$}

Lungenkrebs ist die vermeidbarste neoplastische Erkrankung für Männer und Frauen. Die Inzidenzrate liegt in Deutschland jährlich bei 14.000 . Rauchen ist der Hauptrisikofaktor für Lungenkrebs und in 90\% der Fälle mit der Krankheit assoziiert. Studien haben gezeigt, dass der Zeitpunkt der Diagnosestellung ein günstiger Moment für Rauchstopp-Interventionen ist. Die effektivste Therapie-Methode war dabei eine Kombination aus Verhalten- und Pharmakotherapie (z.B. NET, Bupropion, Vareniclin).

In dieser Studie wurde der Rauchstatus aller resezierten Lungenkrebspatienten aus den Jahren 2011, 2012 und 2013 untersucht. Ein retrospektives, halb-strukturiertes Telefoninterview zu Rauchgewohnheiten und Lebensqualität wurde durchgeführt. 131 Patienten (36,6\% weiblich, Durchschnittsalter 68,7 Jahre) einer städtischen, deutschen Klinik wurden eingeschlossen.

Die Ergebnisse zeigen eine Rückfallrate von 22,3\%, wovon $86,2 \%$ stark abhängige Raucher waren. Eine multivariate Analyse der Kovarianz (MANCOVA) zeigte einen signifikanten Einfluss des Rauchstatus auf die Lebensqualität mit mittlerer Effektstärke (kontrolliert nach Alter, Geschlecht, Lebensumstände, Tumorstadium, Dauer der Rauchabstinenz, Art der Krebstherapie, Operationsmethode und Zeitraum zwischen Untersuchung und OP-Termin). Zwei Drittel aller Patienten sahen keinen Zusammenhang zwischen der Erkrankung und ihrem Rauchverhalten.

Bisher wird die Rauchstoppmotivation und die Langzeitabstinenz auch von lebensbedrohlich erkrankten Menschen in Deutschland nicht umfassend berücksichtigt. Zukünftige Forschungsvorhaben sollten sich auf neue und intensivere Interventionen und psychoedukative Strategien konzentrieren. 


\section{Background \\ $\nabla$}

Smoking is the biggest avoidable health risk in Germany. The annual mortality rate is about 140.000 due to smoking and another 3.000 due to second hand smoke. Smoking prevalence is about 15 millions of over 15 years old Germans, with a recently slightly negative trend for male, but a rising share of female smokers [1-3].

$90 \%$ of patients with lung cancer were smokers and $10-35 \%$ are still active smokers at the time of diagnostic procedures [4-7]. Lung cancer is with a 99\% probability rate a malignant neoplasm, which can be classified into non-small cell lung cancer (NSCLC) (70-80\%) and small cell lung cancer (SCLC) (15-20\%). Primary therapeutic approach for NSCLC at a limited stage is resective surgery [8].

Lung cancer patients are mostly highly addicted, heavy smokers needing a prolonged and more intensive cessation therapy as well as higher doses of withdrawal medication [5, 9].

About two months after "successful" quit attempts, relapse rates show a peak. It is therefore recommended that therapy should be extended until after this critical period. After leaving the clinical surrounding patients struggle to remain smoke free. So far relapse rates of $10 \%$ to $30 \%$ were observed [ $10-13$ ].

For some time - due to contradictory study results - no clear recommendation of the most preferable starting point to stop was available [14], while more recent studies show at least no negative effect to stop before cancer treatment starts $[15,16]$.

Zaman et al. [16] described many advantages of an early cessation attempt for patients with surgical treatments like less post-surgical pulmonary complications, improved wound healing and decreased post-surgical infection risks. The moment of diagnosis is supposed to be a promising teachable moment to quit smoking [5,16-18], and is also an important step at any time for all NSCLC patients to improve their clinical course [19].

\section{Health promotion through quitting smoking}

Numerous physiological parameters may be improved by smoking cessation in relatively short time [20]. If scores like blood pressure, oxygen saturation are corrected, immune system will be reactivated, which will be followed by increased mental and physical capacity [5], tobacco cessation has an overall positive influence on lung cancer patients' status, risk minimizing of postsurgical complications and the onset of secondary or recurrent tumors $[14,16,21]$.

Risk for cardio-respirational comorbidities may be decreased since these smoking related diseases limit further therapeutic options and surgical treatment [19].

Even patients who undergo radio-, chemo- or a radio-chemotherapy profit from smoking cessation; medication doses can be lower and during treatment side effects such as infections (radiopneumonia) are less likely $[19,22]$. However, if lung cancer patients do not stop smoking, their risk to die is doubled [20].

Nicotine replacement therapy (NRT) with its rare side effects and simple and safe handling is suitable for lung cancer patients [5, 23]. A combination of NRT with the antidepressant Bupropion is another option for lung cancer patients, who often also suffer from depressive symptoms $[5,24]$. Varenicline has not been studied in this study cohort so far [25]. Success rates can be doubled if combined with cognitive behavioral group therapy [3, 7,26].

Recent studies on cancer patients and their motivation to quit smoking have shown, that younger patients with an early tumor stage and patients with domestic smoking confrontation were more likely to participate in cessation groups [27]. To include family members and friends within the therapy was an asset in terms of smoke free homes and longterm abstinence $[5,28]$.

\section{Aims and Objectives}

This pilot study examines the smoking status of 131 curatively resected lung cancer patients from 2011-2013. It also aims at detecting positive influential factors on successful and longterm abstinence. So far it is unclear, how many German patients continue to smoke or relapse after surgery and what reasons and environmental circumstances have an impact on this behavior. Since smoking behavior on the other hand is of enormous importance regarding prognostic perspectives, this information is of great practical value.

This study tries to evaluate current smoking prevalence among lung cancer patients and examines (intuitively) used methods to stop and examines knowledge on cessation support options. We try to detect potential therapeutic gaps. In addition we were also asking for data on perceived quality of life among lung cancer patients and in this context, we tried to gain information on grade of addiction, failed quitting attempts and the current motivation to stop. The influence of a successful quit attempt was analyzed statistically regarding psychological well being.

\section{Materials \& Methods \\ $\nabla$}

To gain a maximum of individual information in a reasonable time span, a cross sectional retrospective telephone interview was conducted with resected lung cancer patients from the years 2011, 2012 and 2013 of an urban German lung cancer center. All 300 patients were invited to take part in this study, were informed about anonymity and content of the study and had to sign a written agreement to be contacted up to three times afterwards at their preferred chosen time slot. 131 written agreements were sent back and could therefore be included in this study.

Data were collected via semi structured telephone interviews. Self-administered questions about personal status, course of disease were combined with well established instruments such as SF12 (Short Form 36 Health Survey Questionnaire) [29], Wellbeing Index-WHO5 [30,31] and Fagerstroem Test Nicotine Dependence [32]. To avoid patients' strain as few and as short as possible questions were selected to keep up an average level of 10 minutes per phone call $[12,29]$. Clinical records of all included patients were reviewed for course of disease, co-morbidities and therapeutic options.

Data safety was guaranteed according to Berlin law (Gesetz zum Schutz personenbezogener Daten in der Berliner Verwaltung, Berliner Datenschutzgesetz-BlnDSG, vom 17. Dezember 1990 (GVBl.1991, S. 16, 54). Ethical consent was given by Berlin's physicians' chamber.

Data were processed and analyzed using SPSS ${ }^{\circledR}$ version 19.0. A $5 \%$ level of statistical significance was used. Descriptive statistics were performed on personal and clinical characteristics of patients. Multivariate analysis of variance and covariance were conducted for group differences and effect strengths of single characteristics. 


\section{Results}

131 patients were included in this study ( $36.6 \%$ female; mean age of 68.7 years) (Tab. 1a). The overall response rate is $43.6 \%$; due to a non-German-speaking background, relocation to e.g. nursing homes or fatal progress we could attribute $12 \%$ of non-responders. As expected nearly two thirds of all examined patients were male. $37.9 \%$ of smokers and $59.3 \%$ of ex-smokers agreed upon an association between their lung cancer and their former or current smoking habit (no illustration).

Our results show a relapse rate of $22.1 \%$ (=after the short period of abstinence of surgery). $86.2 \%$ of all examined current smokers scored medium and high nicotine dependencies ( $\bullet$ Tab. 1b).

When we asked about helpful support and motivational reasons to stop smoking smokers and ex-smokers did not differ significantly ( Tab.2a-b).

In $-\mathrm{Tab} .2 \mathrm{c}$ results regarding which cessation methods were used are shown. The majority of smokers and ex-smokers did not use any assisted cessation method. Nicotine replacement

\begin{tabular}{|c|c|c|c|c|}
\hline Variable & \multicolumn{2}{|l|}{$N=131$} & \multicolumn{2}{|l|}{$\%$} \\
\hline \multicolumn{5}{|l|}{ Gender } \\
\hline Male & \multicolumn{2}{|l|}{83} & \multicolumn{2}{|l|}{63.4} \\
\hline Female & \multicolumn{2}{|l|}{48} & \multicolumn{2}{|l|}{36.6} \\
\hline \multicolumn{5}{|c|}{ Smoking status } \\
\hline & Never-smokers & Ex-smokers & Smokers & Total \\
\hline \multicolumn{5}{|l|}{ Gender } \\
\hline Male & 1 & 63 & 19 & 83 \\
\hline Female & 9 & 29 & 10 & 48 \\
\hline Total & 10 & 92 & 29 & 131 \\
\hline
\end{tabular}

Table 1b Smokers categorized by Fagerstroem scores.

\begin{tabular}{|lcr|}
\hline & Number of patients & $\%$ \\
\hline Smoking status & & \\
\hline Ex-smokers & 92 & 70.2 \\
\hline Never-smokers & 10 & 7.6 \\
\hline Smokers (relapsed) & 29 & 22.1 \\
\hline Fagerstroem dependency categories & & \\
\hline $0-3$ low & 4 & 13.8 \\
\hline $4-6$ medium & 12 & 41.4 \\
\hline $7-10$ high & 13 & 44.8 \\
\hline
\end{tabular}

therapy (NRT) is being used to a minor extent, although current smokers do not seem to profit as much as ex-smokers from it.

The time frame of stopping varies between the group of smokers and ex-smokers and is shown in Tab. $\mathbf{2 d}$. The biggest difference between groups can be observed for the time slot "at beginning of therapy"; more smokers seem to postpone the quitting date to start of therapy compared to ex-smokers, who quit more frequently at the time slot of diagnosis.

Table 2a-b Perceived support and motivation to stop in smokers and exsmokers.

$\begin{array}{lll}\begin{array}{l}\text { Number } \\ \text { of Patients }\end{array} & \%\end{array}$

2a: Is there anything that helped you specifically to stop smoking? Smoking status

Ex-smokers

\begin{tabular}{|c|c|c|c|c|}
\hline & No & 77 & 84.6 & 84.6 \\
\hline & Social support & 13 & 14.3 & 98.9 \\
\hline & Sports & 1 & 1.1 & 100.0 \\
\hline & Total & 91 & 100.0 & \\
\hline Missing & & 1 & & \\
\hline Total & & 92 & & \\
\hline \multicolumn{5}{|l|}{ Smokers } \\
\hline & No & 20 & 74.1 & 74.1 \\
\hline & Social support & 5 & 18.5 & 92.6 \\
\hline & Medication & 2 & 7.4 & 100.0 \\
\hline & Total & 27 & 100.0 & \\
\hline Missing & & 2 & & \\
\hline Total & & 29 & & \\
\hline
\end{tabular}

2b: What was your main motivational reason to quit?

Smoking status

Ex-smokers

\begin{tabular}{llrrr} 
& Health concerns & 70 & 79.5 & 79.5 \\
& Social support & 18 & 20.5 & 100.0 \\
\cline { 2 - 5 } & Total & 88 & 100.0 & \\
Missing & & & \\
Total & 92 & & \\
Smokers & & & \\
& Health concerns & 23 & 95.8 & 95.8 \\
& Social support & 1 & 4.2 & 100.0 \\
& Total & 24 & 100.0 & \\
Missing & & 5 & & \\
\hline Total & & 29 & & \\
& & &
\end{tabular}

Table 2c Cessation methods used by smokers and ex-smokers.

\begin{tabular}{|c|c|c|c|c|c|c|c|c|}
\hline Cessation methods & None & NRT & Varenicline & Bupropion & CBT & $\begin{array}{l}\text { Others (acupuncture, } \\
\text { hypnosis, books... }\end{array}$ & Missing & Total \\
\hline Ex-smokers & 77 & 9 & 2 & 0 & 0 & 3 & 1 & 91 \\
\hline$\%$ & 83.7 & 9.8 & 2.2 & 0 & 0 & 3.3 & 1.1 & 100 \\
\hline Smokers & 14 & 7 & 0 & 1 & 1 & 1 & 5 & 24 \\
\hline$\%$ & 48.3 & 24.1 & 0 & 3.4 & 3.4 & 3.4 & 17.2 & 100 \\
\hline
\end{tabular}

Table 2d Time frame of stop smoking in smokers and ex-smokers.

\begin{tabular}{|c|c|c|c|c|c|}
\hline Time frame for quitting & Before diagnosis & At diagnosis & At beginning of therapy & End of therapy & Tota \\
\hline Ex-smokers & 54 & 22 & 15 & 1 & 92 \\
\hline$\%$ & 58.7 & 23.9 & 16.3 & 1.1 & 100 \\
\hline Smokers & 10 & 4 & 9 & 1 & 24 \\
\hline$\%$ & 41.7 & 16.7 & 37.5 & 4.2 & 100 \\
\hline
\end{tabular}


Table 3 WHO 5, SF 12 results for smokers and never-/ex-smokers.

\begin{tabular}{|llccccc|}
\hline Measure & Smoking status & N & Range & M & SD \\
\hline \multirow{2}{*}{ WHO-5 } & Ex-/never-smokers & 102 & $0-25$ & 13.49 & 5.78 \\
\hline \multirow{2}{*}{ SF-12 physical cumulative score } & Smokers & 29 & $0-25$ & 10.48 & 7.94 \\
\hline \multirow{2}{*}{ SF-12 psychological cumulative score } & Ex-/never-smokers & 99 & $15-60$ & 39.06 & 10.32 \\
& Smokers & 29 & $17-64$ & 38.78 & 12.67 \\
& Ex-/never-smokers & 99 & $29-68$ & $\mathbf{5 0 . 7 2}^{*}$ & 10.04 \\
\hline
\end{tabular}

Table4 Effect strength of factor "smoking status" on well being.

\begin{tabular}{|llllll}
\hline Effect & $\boldsymbol{F}^{1}$ & $\boldsymbol{d f}$ & Error $\mathbf{d f}$ & Sig. & Partial Eta-Quadrat \\
\hline MANOVA-results & & & & & \\
\hline Smoking status & 3.642 & 3 & 114.000 & $\mathbf{. 0 1 5}^{1}$ & .087 \\
\hline MANCOVA-results & & & & & \\
\hline Age & .102 & 3 & 106.000 & .959 & .003 \\
\hline Time between date of surgery and survey & .775 & 3 & 106,000 & .510 & .021 \\
\hline Smoking status & 3.698 & 3 & 106.000 & $.014^{1}$ & .095 \\
\hline Mode of therapy & .388 & 3 & 106.000 & .762 & .011 \\
\hline Gender & 2.175 & 3 & 106.000 & .095 & .058 \\
\hline Tumor stage & .869 & 3 & 106.000 & .459 & .024 \\
\hline Surgical method & .634 & 3 & 106.000 & .595 & .018 \\
\hline Social support & 1.564 & 3 & 106.000 & .203 & .042 \\
\hline Period of abstinence & .641 & 3 & 106.000 & .590 & .018 \\
\hline
\end{tabular}

1 Pillai-Spur

In terms of the WHO5 Wellbeing Index, ex-smokers (score= 13.52) were showing higher scores, but not significantly than smokers (score $=10.48)(-$ Tab.3); considering the cut off score for depression of 13 of this instrument, both groups are at risk. Nevertheless even seriously ill patients, who could quit smoking seem to be better off than current smokers taking into account results of SF12 stating significant higher scores in psychological wellbeing for ex-smokers. Scores for physical well being in the SF 12 did not differ significantly, but showed nevertheless a tendency for a positive trend in ex-smokers.

We could attribute our findings (regarding mental wellbeing scores of SF12 and WHO5) performing further statistical analysis (ANOVA, MANOVA) and show a medium influencing effect of smoking abstinence supporting improved psychological well being ( Tab.4).

\section{Discussion \& Conclusion}

$\nabla$

Lung cancer is the leading cause of tobacco-associated mortality in Germany and strongly impacts patient's health-related quality of life.

In a retrospective, semi-structured telephone survey 131 lung cancer patients who were diagnosed and curatively resected in 2011 - 2013, were asked about current smoking status and selfperceived quality of life. Our data show $22 \%$ of lung cancer patients continue smoking after cancer diagnosis and therapy. Descriptive and multivariate statistical analysis indicated a significant overall impact of smoking status on quality of life with a medium effect size. These findings indicate an association between improved mental wellbeing and smoking cessation.

Positive influence of quitting smoking on wellbeing has also been reported here $[13,33,34]$, even for physical outcome recently [35]. Our results underline the underestimation or misinterpre- tation of the impact of smoking on health within this specific population as well as the positive effects of quitting - even in terms of cost effectiveness [36].

Regarding our findings health concerns were the main reason for patients to attempt to stop, while almost every second patient did not accept an association of his/her smoking habit and the current disease. New findings suggest that easy to handle messages e.g. time after waking up before smoking could be an indicator for increased lung cancer risk would reach people with a lack of basic health knowledge [37].

Helpful aspects for quitting could not be named except for social support (7-14\%). Social support was mainly mentioned for (adult) children and (married) partners [38]. Our patients were not expecting or asking for medical support by health care workers with this issue and cessation aid is not offered automatically nor continuously during treatment by every physician $[39,40]$. NRT, Varenicline, Bupropion and a combination of CBT, which have been proven to be very effective on a longterm perspective, have been used only by a minority of less than $3 \%$ in total.

So far these patients felt that stop smoking was more or less "their business", a question of strong will and power of endurance.

Future educational programs for patients need to be considered. A new study found a positive effect of knowledge about second hand smoke for the willingness to quit [41]. It should be investigated if other patient cohorts with high smoking rates (e.g. COPD) have better knowledge of consequences of their smoking behavior to get more information on how patients can be reached, motivated and made aware of their influence on their situation [42-44].

However the relapse rate of $22 \%$ after resection is still high, there is no mandatory stop smoking treatment procedure in Germany for any patients. Nevertheless it is known for a long time, advice by medical workers is still considered to be an effective method 
to increase quitting attempts [43]. Medical staff assumes tobacco cessation often as "too frustrating, no financial reimbursement, have other priorities" [4,45-47]. This can be changed through additional competencies in psychotherapeutic oral skills as well as the insight that little intervention can lead to a positive change [48].

New forms of incentives (e.g. financial gratification) could support future quit attempts in highly addicted patients (and humans coming from a socially low background) even after failed attempts which could also be another step into a more personalized medical care [49-51].

These findings can not be generalized since data was collected only via telephone interviews and our study cohort was rather small in specific details. No objective data like CO levels could have been included to verify patients' statements. Some participants were recalling situations of about 2 years ago, so results may be biased.

The importance of attributing their sickness to their behavior was recently confirmed in this study [52]; taking into consideration genetically relations.

When we were asking ex-smokers about the moment of stopping, we did not get sufficient information if they were already feeling sick or maybe suspecting a serious illness like lung cancer or if they have been exposed to second hand smoke in addition.

Due to small numbers of smokers in our study, no more elaborate data analysis was possible - as: Why would someone try to stop smoking because of health concerns if not accepting an association of lung cancer and smoking; why would you try to stop earlier for health issues and not when you get a sincere diagnosis? Are relapsed smokers in this study really those, who did have highest physical dependencies and no social support at the same time? These questions should be examined in further studies.

Note: Karin Vitzthum, Wulf Pankow, Stephan Eggeling and Stefanie Mache designed this study; Anne Deter and Lucia Thielke carried out data enquiry; Thomas Riemer, Stefanie Mache, Karin Vitzthum und Lucia Thielke carried out data analysis.

\section{Conflict of Interest}

The authors declare that they have no conflict of interest.

\section{References}

1 Blum T, Schonfeld N, Goeckenjan $G$ et al. [Implementation of the German Guideline for the Prevention, Diagnosis, Treatment, and Followup of Lung Cancer in the Federal State of Berlin]. Pneumologie (Stuttgart, Germany) 2013; 67: 118-122

2 Batra A. Treatment of tobacco dependence. Deutsches Arzteblatt international 2011; 108: 555-564

3 Andreas S, Rittmeyer A, Hinterthaner $M$ et al. Smoking cessation in lung cancer - achievable and effective. Deutsches Arzteblatt international 2013; 110: 719-724

4 Cooley ME, Sipples RL, Murphy M et al. Smoking cessation and lung cancer: oncology nurses can make a difference. Seminars in oncology nursing 2008; 24: $16-26$

5 Cataldo JK, Dubey S, Prochaska JJ. Smoking cessation: an integral part of lung cancer treatment. Oncology 2011; 78: 289-301

6 Park ER, Japuntich S, Temel J et al. A smoking cessation intervention for thoracic surgery and oncology clinics: a pilot trial. J Thorac Oncol 2011; 6: 1059-1065

7 Fiore MC, Schroeder SA, Baker TB. Smoke, the chief killer - strategies for targeting combustible tobacco use. N Engl J Med 2014; 370: 297-299
8 Mong C, Garon EB, Fuller C et al. High prevalence of lung cancer in a surgical cohort of lung cancer patients a decade after smoking cessation. Journal of cardiothoracic surgery 2011; 6: 19

9 Cooley ME, Emmons KM, Haddad R et al. Patient-reported receipt of and interest in smoking-cessation interventions after a diagnosis of cancer. Cancer 2011; 117: 2961 - 2969

10 Cooley ME, Sarna L, Brown JK et al. Tobacco use in women with lung cancer. Ann Behav Med 2007; 33: $242-250$

11 Cooley ME, Wang $Q$ Johnson BE et al. Factors associated with smoking abstinence among smokers and recent-quitters with lung and head and neck cancer. Lung cancer (Amsterdam, Netherlands) 2012; 76: $144-149$

12 Wong WS, Fielding $R$. Prevalence of chronic fatigue among Chinese adults in Hong Kong: a population-based study. Journal of affective disorders 2010; $127: 248-256$

13 Daniel M, Keefe FJ, Lyna P et al. Persistent smoking after a diagnosis of lung cancer is associated with higher reported pain levels. J Pain 2009; 10: $323-328$

14 Vaporciyan AA, Merriman $K W$, Ece $F$ et al. Incidence of major pulmonary morbidity after pneumonectomy: association with timing of smoking cessation. The Annals of thoracic surgery 2002; 73: 420 425; discussion 425-426

15 Raupach T, Quintel M, Hinterthaner M. [Preoperative smoking cessation in patients with lung cancer]. Pneumologie (Stuttgart, Germany) 2010; 64: $694-700$

16 Zaman M, Bilal H, Mahmood S et al. Does getting smokers to stop smoking before lung resections reduce their risk? Interactive cardiovascular and thoracic surgery 2012; 14: 320-323

17 Poghosyan H, Kennedy SL, Cooley ME. The impact of computed tomography screening for lung cancer on smoking behaviors: a teachable moment? Cancer nursing 2012; 35: 446-475

18 Park ER, Japuntich SJ, Rigotti NA et al. A snapshot of smokers after lung and colorectal cancer diagnosis. Cancer 2012; 118: 3153-3164

19 Cooley ME, Sarna L, Kotlerman J et al. Smoking cessation is challenging even for patients recovering from lung cancer surgery with curative intent. Lung cancer (Amsterdam, Netherlands) 2009; 66: 218-225

20 Parsons A, Daley A, Begh $R$ et al. Influence of smoking cessation after diagnosis of early stage lung cancer on prognosis: systematic review of observational studies with meta-analysis. BMJ (Clinical research ed 2010; 340: b5569

21 Goeckenjan G, Sitter H, Thomas $M$ et al. [Prevention, diagnosis, therapy, and follow-up of lung cancer. Interdisciplinary guideline of the German Respiratory Society and the German Cancer Society - abridged version]. Pneumologie (Stuttgart, Germany) 2011; 65: e51 - e75

22 de Bruin-Visser JC, Ackerstaff AH, Rehorst $H$ et al. Integration of a smoking cessation program in the treatment protocol for patients with head and neck and lung cancer. Eur Arch Otorhinolaryngol 2012; 269: 659665

23 Loh WY, Piper ME, Schlam TR et al. Should all smokers use combination smoking cessation pharmacotherapy? Using novel analytic methods to detect differential treatment effects over 8 weeks of pharmacotherapy. Nicotine Tob Res 2012; 14: 131 - 141

24 Hering T, Andres J, Gebhardt R et al. [Smoking cessation in pneumological routine care]. Pneumologie (Stuttgart, Germany) 2011; 65: 692696

25 Jimenez-Ruiz C, Berlin I, Hering T. Varenicline: a novel pharmacotherapy for smoking cessation. Drugs 2009; 69: 1319-1338

26 Andreas S, Herth FJ, Rittmeyer A et al. [Smoking, chronic obstructive pulmonary disease and lung cancer]. Pneumologie (Stuttgart, Germany) $2007 ; 61: 590-594$

27 Cooley ME, Finn KT, Wang $Q$ et al. Health behaviors, readiness to change, and interest in health promotion programs among smokers with lung cancer and their family members: a pilot study. Cancer nursing 2013; 36: 145-154

28 Bastian LA, Fish LJ, Peterson BL et al. Proactive recruitment of cancer patients' social networks into a smoking cessation trial. Contemporary clinical trials 2011; 32: 498-504

29 Innocenti F, Del Taglia B, Coppa A et al. Quality of life after mild to moderate trauma. Injury 2015; 46: $902-908$

30 Heun R, Burkart M, Maier W et al. Internal and external validity of the WHO Well-Being Scale in the elderly general population. Acta psychiatrica Scandinavica 1999; 99: $171-178$

31 Bech P, Olsen LR, Kjoller $M$ et al. Measuring well-being rather than the absence of distress symptoms: a comparison of the SF-36 Mental 
Health subscale and the WHO-Five Well-Being Scale. International journal of methods in psychiatric research 2003; 12: 85 -91

32 Heatherton TF, Kozlowski LT, Frecker RC et al. The Fagerstrom Test for Nicotine Dependence: a revision of the Fagerstrom Tolerance Questionnaire. British journal of addiction 1991; 86: 1119-1127

33 Poghosyan $H$, Sheldon $L K$, Leveille $S G$ et al. Health-related quality of life after surgical treatment in patients with non-small cell lung cancer: a systematic review. Lung cancer (Amsterdam, Netherlands) 2013; 81: $11-26$

34 Hering T. [Smoking cessation improves quality of life]. MMW Fortschritte der Medizin 2014; 156: 68-69

35 Dobson Amato KA, Hyland A, Reed $R$ et al. Tobacco Cessation May Improve Lung Cancer Patient Survival. J Thorac Oncol 2015; 10: 10141019

36 Poghosyan $H$, Bell JF, Joseph JG et al. The association between having a first-degree family history of cancer and smoking status. Preventive medicine 2014; 66: 12 - 16

$37 \mathrm{Gu} F$, Wacholder S, Kovalchik S et al. Time to smoke first morning cigarette and lung cancer in a case-control study. Journal of the National Cancer Institute 2015; 106: dju118

38 Regan T, Carey M, Bryant J et al. Prevalence and correlates of current smoking among medical oncology outpatients. Psycho-oncology 2015

39 Weaver KE, Danhauer SC, Tooze JA et al. Smoking cessation counseling beliefs and behaviors of outpatient oncology providers. The oncologist 2015; 17 : 455-462

40 Warren GW, Cummings KM. Tobacco and lung cancer: risks, trends, and outcomes in patients with cancer. American Society of Clinical Oncology educational book/ASCO American Society of Clinical Oncology 2015: $359-364$

41 Nicholson $A K$, Borland $R$, Couzos $S$ et al. Smoking-related knowledge and health risk beliefs in a national sample of Aboriginal and Torres Strait Islander people. The Medical journal of Australia 2015; 202: $45-50$
42 Slatore CG, Au DH, Hollingworth W. Cost-effectiveness of a smoking cessation program implemented at the time of surgery for lung cancer. J Thorac Oncol 2009; 4: 499-504

43 Fiore MC, Jorenby DE, Schensky AE et al. Smoking status as the new vital sign: effect on assessment and intervention in patients who smoke. Mayo Clinic proceedings 1995; 70: 209-213

44 van der Aalst CM, de Koning HJ, van den Bergh KA et al. The effectiveness of a computer-tailored smoking cessation intervention for participants in lung cancer screening: a randomised controlled trial. Lung cancer (Amsterdam, Netherlands) 2012; 76: 204-210

45 Cooley ME, Lundin R, Murray L. Smoking cessation interventions in cancer care: opportunities for oncology nurses and nurse scientists. Annual review of nursing research 2009; 27: 243-272

46 Anderson JE, Jorenby DE, Scott WJ et al. Treating tobacco use and dependence: an evidence-based clinical practice guideline for tobacco cessation. Chest 2002; 121: $932-941$

47 Raupach T, Merker J, Hasenfuss G et al. Knowledge gaps about smoking cessation in hospitalized patients and their doctors. Eur J Cardiovasc Prev Rehabil 2011; 18: 334-341

48 Hildebrand JR, Sastry S. "Stop smoking!" Do we say it enough? Journal of oncology practice/American Society of Clinical Oncology 2013; 9: $230-232$

49 Tappin $D$, Bauld $L$, Purves $D$ et al. Financial incentives for smoking cessation in pregnancy: randomised controlled trial. BMJ (Clinical research ed) 2015; 350: h134

50 Zeng $F$, Chen $C I$, Mastey $V$ et al. Effects of copayment on initiation of smoking cessation pharmacotherapy: an analysis of varenicline reversed claims. Clinical therapeutics 2011; 33: 225-234

51 Cahill K, Perera R. Competitions and incentives for smoking cessation. The Cochrane database of systematic reviews 2011: CD004307

52 Carr SR, Akerley W, Hashibe $M$ et al. Evidence for a genetical contribution to non-smoking-related lung cancer. Thorax 2015 pii: thoraxjnl2014-206584. DOI 10.1136/thoraxjnl-2014-206584 